\title{
A mediação literária da realidade colonial: representações da realidade nas literaturas africanas em português
}

\author{
Inocência Mata*
}

\begin{abstract}
Resumo
As literaturas africanas, enquanto sistemas, são subsidiárias de diferentes estéticas, desde os anos 30 aos anos 70, através de diferentes cartografias de mediações da realidade. É que a partir da ideologia nacionalista, o discurso literário e o metaliterário foram-se constituindo como uma das faces visíveis da luta de libertação, juntamente com a frente diplomática e a guerra de guerrilha que eram como frentes externas da luta. $\mathrm{O}$ objectivo deste texto é desvelar, quase meio século depois, após o 25 de Abril que levou à Revolução dos Cravos em Portugal e acelerou as independências políticas das colónias portuguesas de África (1973-1975), os meandros dessa mediação realista e apreender a potencialidade anticolonial da estética que efectuou o registo desse tempo em obras de diferentes origens geoculturais, como as africanas, produzidas, tal como as portuguesas, sob o signo da censura.
\end{abstract}

Palavras-chave: Realismos. Mediação realista. Representação. Estética anticolonial.

Claro que o Realismo atravessa os séculos, não no sentido estrito da escola, mas na acepção mais vasta de categoria literária.

Alexandre Pinheiro Torres (1977, p. 27)

\section{Realismos e "documentos" literários}

No radicalismo de uma época de intolerância político-ideológica, como a época vivida nos anos 30-70 do século XX português, dominado pela ideologia (imperial e ditatorial) do Estado Novo, a literatura foi instância importante que

\footnotetext{
* Universidade de Lisboa. Doutora em Letras pela Universidade de Lisboa, com pós-doutoramento em Estudos Pós-coloniais (Postcolonial Studies, Identity, Ethnicity, and Globalization, Universidade de Califórnia, Berkeley). É investigadora do Centro de Estudos Comparatistas, núcleo de excelência, segundo FCT-PT (Fundação para a Ciência e a Tecnologia, Portugal). Reside actualmente em Macau onde é professora na Universidade de Macau, ao abrigo de uma licença especial da Universidade de Lisboa.
} 
buscou registar a realidade através de uma representação objectiva. Era preciso perseguir uma nova ordem política e social (na metrópole e nas colónias) e a transfiguração da realidade em arte (no caso em texto) foi a estratégia plausível para a representação da realidade sócio-política para o campo literário, para parafrasear Miguel Real. ${ }^{1}$ Quase meio século depois, após o 25 de Abril, que levou à Revolução dos Cravos e acelerou as independências políticas das colónias portuguesas de África (1973-1975), como é possível entender esta estética - “estilo realista" na expressão de Miguel Real - e apreender a potencialidade anticolonial da estética que efectuou o registo desse tempo em obras de diferentes origens geoculturais, como as africanas, produzidas, tal como as portuguesas, sob o signo da censura?

O propósito de muitos escritores visava uma aproximação à realidade das relações político-sociais, mesmo quando essa realidade fosse apreendida através de universos mais interiores, mais íntimos, recordações do passado ou vivências pessoalizadas e colectivizadas do quotidiano. Situando-se a nível da compreensão do realismo como "categoria de escrita", ligada à função de representação figurativa do fenómeno representado (TORRES, 1977, p. 47), mas recuperando pressupostos do realismo como "movimento literário", pode dizer-se que a "epistemologia" realista se situava entre a arte engagée e a "arte autotélica" - já Eça de Queirós definia o realismo como “ a negação da arte pela arte”, sendo, portanto, "a crítica do homem (...) para condenar o que houver de mau na (...) sociedade” (QUEIRÓS, 1871, p. 127). Embora Raymond Williams (2014, p.201) lembre que "há um sentido consideravelmente diferente, ativo, de mimesis, que não é absolutamente reflexo, mas um processo de compreensão, interpretação e transformação", os escritores buscavam denunciar a realidade, no contexto de um regime que censurava qualquer actividade de informação, "mimetizando-a" para a divulgar, dá-la também a conhecer, servindo a escrita literária como mediadora de conteúdos referenciais. Neste contexto, escritores houve que afirmaram a sua "filosofia estética", como Alves Redol que, no pórtico de Gaibéus (1939), declara: "Este romance não pretende ficar na literatura como obra de arte. Quer ser, antes de tudo, um documentário humano fixado no Ribatejo. Depois disso, será o que os outros entenderem."

1 A afirmação de Miguel Real é: "Em harmonia com um tempo cosmopolitae tecnocrataglobal, o estilo realista (transfiguração da realidade social para o campo narrativo) é atualmente dominante nos romances portugueses, inclusive nos romances históricos" (REAL, 2012, p. 66). 
O que se procurava, por outro lado, era não idealizar a realidade, antes representando de forma histórica a sociedade, "retratando" ("arte que nos pinta a nossos próprios olhos", dissera Eça) os seus conflitos e agências, as suas lutas contra as injustiças e a precariedade económica, na Europa, em África ou nas Américas - enfim, tanto no Portugal metropolitano e nas suas colónias quanto no nordeste brasileiro. Tratava-se de um (novo) realismo em que, através da arte (a escrita literária, no caso), se procedia a uma intervenção social com vista à sua transformação:

Mais do que uma corrente intelectual, do que uma resposta a este ou aquele movimento artístico, mais do que a expressão de uma força política, o movimento neo-realismo foi a expressão de uma solidariedade, de uma tomada de posição perante o sofrimento agravado do povo português. (MACHADO, 2012).

Numa perspectiva de "arte "inútill", da "arte pela arte", parecia tratar-se de uma "'excessiva' preocupação de muitos escritores com a representação da realidade social e política do país" (PINTO, 2003), que Alexandre Pinheiro Torres sintetizaria referindo-se à crítica protagonizada pela Presença: "desde que uma obra manifestasse preocupações de carácter social, ou ela fosse encarada e criticada de um ponto de vista sociológico, já não pertenceria ao domínio da Literatura mas ao da Sociologia" (TORRES, p. 1983, p. 44)". No entanto, essa "submissão à realidade", nas palavras de Bernardo de Carvalho (apud PINTO, 2003) referindo-se à actual literatura brasileira, apontava para dois princípios: por um lado, representar as diferentes dimensões das alegorias políticas que então se vivia e, por outro, denunciar, através dessas representações, o mundo opressivo que se vivia na metrópole e nas colónias. E apesar de não se pensar essa função representativa da arte como uma estética de conteúdos, essa convergência de propósitos aproximou a escrita política antifascista, dos escritores portugueses, da anticolonial, dos africanos. Ambos os lados - metropolitano e imperial (ainda que Alexandre Pinheiro Torres tenha falado de "metrópoles literárias" e "colónias literárias" como um esquematismo) - propugnavam por uma dimensão extratextual das suas escritas, que representavam, reivindicavam e propunham uma transformação da realidade, representando uns o confronto entre operários/ camponeses (jornaleiros) e patrões/latifundiários, e outros o antagonismo entre colonizados/trabalhadores e colonizadores/patrões. 
Assim, embora partindo de lugares de enunciação diferentes, esses escritores buscavam protestar contra a dominação social (fosse o africano colonizado ou o assalariado das cidades e do campo), pondo ênfase na força das classes subalternas e na sua capacidade de resistência e de transformação da situação, contrariando o determinismo político e social em que parecia assentar o humanismo burguês, contra o qual reagia o "novo humanismo", de que a expressão artístico-literária seria o neo-realismo, segundo Alexandre Pinheiro Torres (1977, p. 15). Não é, pois, temerário entender os pressupostos ideológicos e estéticos dessa proposta artística prevalecente num Portugal não apenas colonial porém também fascista, segundo uma perspectiva renovada, pós-colonial, de forma a cruzar as histórias dos diferentes espaços textualizados. É neste contexto que se entende que, ao lado de obras de escritores portugueses, Ilha de nome santo (1942), de Francisco José Tenreiro, obra que marca a modernidade literária são-tomense e introduz o movimento da negritude no mundo da língua portuguesa, tenha sido a nona publicação da colecção "Novo Cancioneiro", de Coimbra, um grupo do movimento neo-realista proponente de uma poesia de carácter social.

\section{A literatura anticolonial como "arte-esperança"}

É nesse clima de cruzamentos ideo-estéticos que as literaturas africanas se "sistematizaram". A partir da ideologia nacionalista, o discurso literário e o metaliterário foram-se constituindo como uma das fases visíveis da luta de libertação, juntamente com a frente diplomática e a guerra de guerrilha que eram as frentes externas da luta. Porém, não deve causar estranheza que, embora essa escrita pudesse estar condicionada pela premência do "combate", autores houve que não aderiram a estratégias ou a formas de contestação mais ostensivas (por opção ideológica ou por limitações contextuais). E, mesmo considerados partícipes da cosmogonia literária nacional, alguns (como Mário António, Angola; Rui Knopfli, Moçambique; ou Sum Marky, São Tomé e Príncipe) terão sido subvalorizados pela "instituição literária" nacionalista, de que faziam parte escritores, mas também críticos e editores, acabando por não integrar esse subsistema da literatura nacional. Com efeito, uma das instâncias da instituição literária foi, durante esse tempo, marcada por um funcionamento (quase) inevitavelmente ideológico, "consagrando" a produção que se realizava sob o signo de um projecto alicerçado numa escrita de afirmação de uma identidade cultural - que deve ser sempre 
entendida como construção intelectual e discursiva e não propriamente como representação da realidade, muitas vezes assumida como histórica.

Em todo o caso, considerado em qualquer nível, o discurso de resistência muito devia a estéticas cujo funcionamento permitia a representação dos antagonismos sócio-económicos e políticos (embora nem sempre de autoafirmação identitária). Na altura, o neo-realismo e a negritude eram paradigmas estéticos que possibilitaram aos escritores, africanos e portugueses, a mediação da realidade sócio-política, económica e cultural de um Portugal colonial sob o signo da ditadura, com os corolários do racismo, da discriminação étnica e social, da repressão e do cerceamento da liberdade de expressão. É importante entender, neste contexto, paradigma como "um campo apreendido de conhecimento, de fato, de um objeto de conhecimento, com base em certas hipóteses fundamentais e que carrega consigo definições de métodos apropriados para a descoberta e o estabelecimento de um conhecimento desse tipo" (WILLIAMS, 2014, p. 195). Com efeito, essas ideologias estéticas permitiram, em nível de objectivo crítico prospectivo, actualizar o discurso sobre uma realidade duplamente dominada, por relações de poder colonial e de classe. Sobre essa relação estreita entre estas duas estéticas, diz Pires Laranjeira:

(...) o colonizado insere-se na cadeia de produção económica enquanto elemento básico de produção material, como trabalhador que gera riqueza de que outros se apropriam (o colonizador e o colonialista, português ou gestor multinacional). Estes, detentores do poder sócio-político e económico, tendem a negar a riqueza cultural dos povos africanos e mesmo a recusar a sua existência, pelo que impõem os padrões exógenos de cultura dos dominados. (LARANJEIRA, 1995, p. 358).

Um dos exemplos ostensivos desse cruzamento de estéticas encontra-se na obra de António Jacinto, particulamente em Poemas (1961), particularmente em "Monangamba":

Naquela roça grande não tem chuva

é o suor do meu rosto que rega as plantações:

Naquela roca grande tem café maduro

e aquele vermelho-cereja

são gotas do meu sangue feitas seiva.

(...) 
Quem dá dinheiro para o patrão comprar

máquinas, carros, senhoras

e cabeças de pretos para os motores?

Quem faz o branco prosperar, ter barriga grande - ter dinheiro?

- Quem?

(...)

(JACINTO apud FERREIRA, 1988, p. 135-136)

É a voz de um trabalhador - negro e contratado, o que não é despiciendo, pois remete imediatamente para a situação colonial e para a completa desumanização do africano - que tem a consciência do seu lugar na máquina capitalista como motor do sistema. Além disso, trata-se de um poema em que à reivindicação da terra $\mathrm{e}$ da dignificação da condição do trabalhador se junta, por um lado, a diálectica da liberdade e da libertação e, por outro, a afirmação cultural:

$\mathrm{E}$ as aves que cantam, os regatos de alegre serpentear e o vento forte do sertão responderão:

- "Monangambééé..."

Ah! Deixem-me ao menos subir às palmeiras

Deixem-me beber maruvo, maruvo e esquecer diluído nas minhas bebedeiras

- "Monangambééé..." (JACINTO apud FERREIRA, 1988, p. 135-136)

E se no final a voz do contratado ecoa pelo mundo colectivizando a "lamentação", no "Poema de alienação" o poeta apresenta a "realidade" de diferentes grupos profissionais no seu quotidano (a quitandeira, a peixeira, o ardina, o cauteleiro, a lavadeira, a prostituta, o criado/empregado doméstico, o contratado/monamgamba, o estivador, enfim), revelando histórias individuais que vão compondo a gramática da subalternidade, da exploração e da espoliação, ao mesmo tempo que vai expondo os diferentes tipos de precariedade nas relações de poder com o dominador (seja o colonizador seja o patrão), para além da sua profissão, lugar, cor ou etnia, para concluir:

Mas o meu poema não é fatalista

o meu poema é um poema que já quer 


\author{
e já sabe \\ o meu poema sou eu-branco \\ montado em mim-preto \\ a cavalgar pela vida.
}

(JACINTO apud FERREIRA, 1988. p.132, 133)

O que se canta são as classes mais baixas, de trabalhadores, sejam assalariados como o ardina, sejam escravizados como o monamgamba e o africano indígena, rusgado e desumanizado pela política do indigenato: ${ }^{2}$

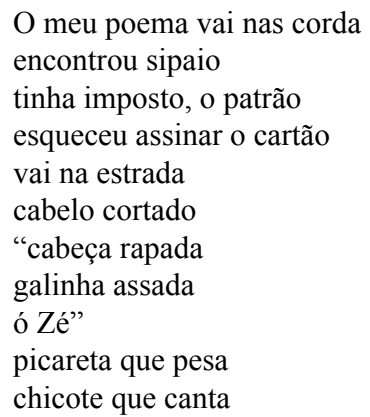

(JACINTO apud FERREIRA, 1988. p.132, 133)

Tal era possível - e é essa realidade da condição de não-cidadão do africano negro que a literatura se propõe denunciar - porque era determinado pelo colonizador que "os nativos das províncias portuguesas da África continental se [encontram] ainda em determinado grau inferior de civilização" (FERREIRA; VEIGA, 1957, p. 11). Eram, afinal, "gentes do mato", com menos direitos do que qualquer outro subalterno, o ardina, por exemplo - embora este igualmente subalterno até pela expressão dialectal da sua fala: "olha a probíncia" "diááário", claramente uma pronúncia de um ardina branco, metropolitano do Norte de Portugal... Era, pois, necessário apresentar a situação realisticamente, até com sinais de identificação geral, como é a canção que é de conhecimento popular... Vemos, portanto, que, sem neutralizar a luta de classes que opõe o trabalhador ao patrão, a questão colonial está explícita na literatura africana dos anos 3070, e ainda mais nos poemas mais "marxistas", na medida em que não apenas transmitiam uma "mensagem" revolucionária, mas revelavam as estratégias de mudança e levavam o leitor à consciencialização e a uma tomada de posição. É por isso que se pode considerar a literatura anticolonial como "arte esperança".

2 Estatuto dos Indígenas Portugueses (1954-1961), segundo o Decreto-Lei nº 39.666. 
É-o no sentido em que essa literatura tem um duplo efeito ético: leva não apenas à consciência da situação (se o leitor é alheio a essa situação), mas pode também promover a acção. Sobre isso diz Terry Eagleton em Marxismo e crítica literária:

(...) o artista revolucionário não deve aceitar de modo indiscriminado as forças de produção artística existentes, mas sim desenvolver e revolucionar tais forças. Ao fazer isso, ele cria novas relações sociais entre o artista e o público; ele supera a contradição que limita as forças artísticas, potencialmente disponíveis a todos, à propriedade privada de poucos. (...) $\mathrm{O}$ artista verdadeiramente revolucionário, portanto, nunca se ocupa apenas com o objeto artístico, mas com os meios da sua produção. $\mathrm{O}$ "engajamento" não se limita à apresentação de opiniões políticas corretas pela arte; ele se revela no grau em que o artista reconstrói as formas artísticas à sua disposição, transformando autores, leitores e espectadores em colaboradores. (EAGLETON, 2011, p. 111-112).

E, neste contexto, quão "revoltado" não se sentirá o leitor de "Monamgamba" (António Jacinto, Angola), de A vida verdadeira de Domingos Xavier (Luandino Vieira, Angola)? Quão "mobilizado" não se sentirá o leitor de "Adeus à hora da largada" (Agostinho Neto, Angola), de "Avó Mariana” (Alda Espírito Santo, São Tomé e Príncipe) ou de "Ninguém” (José Craveirinha, Moçambique)?

\author{
Andaimes \\ até ao décimo quinto andar \\ do moderno edifício de betão armado. \\ O ritmo \\ florestal dos ferros erguidos \\ arquitectonicamente no ar \\ e um transeunte curioso \\ que pergunta: \\ - Já caiu alguém dos andaimes? \\ O pousado ronronar \\ dos motores a óleos pesados \\ e a tranquila resposta do senhor empreiteiro: \\ Ninguém. Só dois pretos. \\ (CRAVEIRINHA, 2002, p.111.)
}

\title{
3 Mediações (neo)realistas (e) nacionalistas
}

Se de Eça de Queirós a Alves Redol existe uma continuidade em relação à 
representação da realidade, que permite a "reprodução" do "mundo-que-sevê (não outro)", com "objectividade" e "impersonalidade", parece razoável considerar que "o Realismo atravessa séculos" (TORRES, 1977, p. 27). Porém, há que considerar que ao longo dos tempos essa continuidade foi-se renovando e superando nas suas actualizações conforme a realidade, permitindo aberturas ao processo de representação figurativa da realidade. Essa categoria permite ver na mediação literária uma forma de reflexão sobre a sociedade: da representação figurativa da sociedade à constituição da literatura como espelho da realidade, de que o texto se faz reflexo de conflitos sociais, e à literatura como representação absoluta dos antagonismos históricos que opõem os grupos humanos (e não apenas classes sociais). A mediação realista sempre se instituiu como consciência autoral que se projecta num "eu" enunciador (narrativo ou lírico) que busca uma nova ordem política, seja burguesa, democrática e socialista, seja nacional, fundada, ou consequente a, na vontade transformadora do homem - fundada, enfim, no sentido da libertação.

Quer no Portugal oitocentista da decadência monárquica e burguesa, no salazarento Portugal colonial atravessado "por um intenso efeito de contestação de desconstrução das instituições dominantes do Estado Novo, de fortíssima crítica à situação da Guerra Colonial (1961-1974) (REAL, 2012, p. 95), quer num Portugal imperial em que os colonizados reivindicavam uma nova ordem política através da afirmação da diferença cultural e ética (e também de armas nas mãos) com vista à independência, essa mediação literária foi sempre no sentido da representação dos conflitos históricos e sociais prevalecentes na sociedade: Os Maias (1888), Os gaibéus (1939), Uma abelha na chuva (1953), O anjo ancorado (1958), A vida verdadeira de Domingos Xavier (1961), No altar da lei (1962), "Monangamba" (Poemas, 1961), "Manifesto imaginado de um contratado" (O Útero da Casa, 2004) - são todos textos em que a estrutura sóciopolítica é contestada, desafiada, resgatada de uma história nem sempre conhecida ou omitida do discurso historiográfico. Essa estrutura textual propõe-se "objectiva" na sua representação (por objectiva quer-se entender aqui impessoal) e apresentada por meio de um dispositivo que permite "recriar" a realidade em foco (até com recorrência a técnicas de dramatização, como no caso de "Manifesto imaginado de um contratado"). Nem sempre essa representação impulsiona a transformação (Basílio continua a ser o mesmo egoísta e inconsequente depois da morte de Luísa, em O primo Basílio, assim como em As mulatinhas (1973) do são-tomense Sum 
Mary, o contratado Tamaleia não consegue fugir do seu destino: morrer na ilha para onde fora levado, depois de rusgado na sua terra, Moçambique). Mas em outros textos existe uma realidade alternativa que claramente se apresenta como possível:

\author{
(...) \\ Amanhã \\ entoaremos hinos à liberdade \\ quando comemorarmos \\ a data da abolição desta escravatura \\ Nós vamos em busca de luz \\ os teus filhos Mãe \\ (todas as mães negras \\ cujos filhos partiram) \\ vão em busca de vida.
}

(AGOSTINHO NETO, 1974, p. 47-48)

No entanto, leia-se "Poema da farra", de Mário António:

Quando li Jubiabá

me cri António Balduíno.

Meu Primo, que nunca o leu

ficou Zeca Camarão.

(...)

Que moça que ele levou!

Cabrita que vira os olhos.

Meu Primo, rei do musseque:

Eu praqui olhando só!

Meu primo tá segredando:

Nossa Senhora da Ilha

ou que outra feiticeira?

A moça o acompanhando.

Zé Camarão a levou:

E eu para aqui a secar.

E eu para aqui a secar.

(ANTÓNIO, 2016)

Neste poema, o que parece relevante é a representação de uma mundividência gregária, de uma sociabilidade nativista em que a consciência social se torna assertiva. É verdade que o ostensivo intertexto com Jubiabá, de Jorge Amado, é significativo e confere ao poema uma dimensão política inescapável. Porém, a 
implementação de uma "mudança real", que conduziria a uma nova realidade social, não se efectua, o que aproxima este tão emblemático poema da angolanidade de Mário António - e algumas outras propostas textuais - de um "novo humanismo" nas relações sociais que, por oposição ao "humanismo burguês" de oitocentos, pretende uma "libertação e igualdade concretas do homem" (TORRES, 1977, p. 15); mas afasta-o da visão transformadora que advoga um reajustamento social assente na força motriz do grupo social deserdado, portanto uma visão dialéctica neo-realista, de contaminação marxista e matriz subversiva, como vemos na ficção de Luandino Vieira ou na poesia de Agostinho Neto. A diferença reside no facto de que na obra destes africanos não apenas se escrevia (sobre) "a humanidade do Negro" [mas também] a desumanidade da colonização". (TORRES, 1977, p. 217).

\section{Em jeito de conclusão: cartografias de mediações da realidade}

Para além da representação realística das condições sócio-económicas, a produção literária dos anos 40-50-60 de autores africanos aliava à representação dos conflitos sociais a exortação à resistência e a reivindicação da pátria, que passava também pela afirmação da diferença cultural, constituindo-se em discurso nacionalista. No entanto, se então essa literatura se actualizava através de temas, ideologemas, símbolos e estratégias discursivas que configuravam uma retórica de resistência antifascista, nem sempre essa retórica se conjugava com a anticolonial. Assim, escritores houve que, não sendo nacionalistas, contribuíram de forma decisiva para a construção do sistema sem um discurso anticolonial de reivindicação pátria, embora com uma escrita de forte crítica social, que narrava (através da representação ou da expressão) a história acontecida sob o signo da censura. Pode-se, nesse contexto, falar de resistência aquém do nacionalismo. 


\title{
The literary mediation of colonial reality: Representations of reality in African literatures in Portuguese
}

\begin{abstract}
From the 1930s to the 1970s, African literatures were the subsidiaries of different aesthetics owing to the different mappings of reality mediations. In originating from nationalist ideology, literary and metaliterary discourse worked as one of the visible faces of the liberation struggle together with the diplomatic front and guerrilla war as the external fronts of the struggle. Almost half a century later, after the 25 April Carnation Revolution of 1974 which sped up the political independence of the African Portuguese colonies (1973-1975), this paper aims at unveiling the intricacies of realistic mediation and [attempts to] grasp the anticolonial potentiality of this aesthetic which emerged as the register of the era and was patent in work coming from different geographical and cultural origins that were both African and Portuguese, and bore the stamp of censorship.
\end{abstract}

Keywords: Realism. Realistic mediation. Representation. Anticolonial aesthetic. aesthetic.

\section{Referências}

ANTÓNIO, Mário. Poema da farra. Disponível em: http://www.jornaldepoesia. jor.br/mat01.html. Acesso em: 20/11/2016.

AGOSTINHO NETO, António. Adeus à hora largada. In. AGOSTINHO NETO, António. Sagrada esperança. Lisboa: Livraria Sá da Costa Editora, 1974, p. 4748.

ALVES REDOL, António. In. Artigos de apoio Infopédia [em linha]. Porto: Porto Editora, 2003-2016. [consult. 2016-11-20 11:05]. Disponível na Internet: https:// www.infopedia.pt/\$alves-redol

CRAVEIRINHA, José. Obra poética. Maputo: Imprensa Universitária.

EAGLETON, Terry. Marxismo e crítica literária. São Paulo: Editora UNESP, 2011.

FERREIRA, Manuel. No reino de Caliban II. Angola e São Tomé e Príncipe. Lisboa: Plátano Editora Sá. 1988.

JACINTO, António. Monangamba. In: FERREIRA, Manuel. No reino de Caliban II. Angola e São Tomé e Príncipe. Lisboa: Plátano Editora Sá. 1988, p. 135-136. JACINTO, António. Castigo pro comboio malandro. In: FERREIRA, Manuel. No 
reino de Caliban II. Angola e São Tomé e Príncipe. Lisboa: Plátano Editora. 1988, p.132, 133.

JACINTO, António. Poema de alienação. In: FERREIRA, Manuel. No reino de Caliban II. Angola e São Tomé e Príncipe. Lisboa: Plátano Editora, 1988

FERREIRA, José Carlos Ney; VEIGA, Vasco Soares da. Estatuto dos indígenas portugueses das províncias da Guiné, Angola e Moçambique. Anotado. 2a . ed. Lisboa: editora, 1957.

LARANJEIRA, Pires. A negritude africana de língua portuguesa. Porto: Edições Afrontamento, 1995.

MACHADO, João. Uma breve abordagem ao Neo-Realismo. In: Esquerda.Net. Dossier 172: o neo-realismo em Portugal. 24 de fev. 2012. http://www.esquerda. net/dossier/uma-breve-abordagem-ao-neo-realismo. Acesso em: 30 abr. 2016.

PINTO, Manuel da Costa. Geração 90, submissão à realidade ou guerrilha literária? Folha de São Paulo. Ilustrada, sábado, 02 de agosto de 2003.

QUEIRÓS, Eça. A literatura nova - o realismo como nova expressão de arte. $4^{\mathrm{a}}$. Conferência do Casino, 12 de junho de 1871. In: CAMPOS MATOS (Org. e Coord.). Dicionário de Eça de Queirós. Lisboa: Editorial Caminho, 1988.

REAL, Miguel. Historiografia: Morte ao realismo! Viva o realismo! In: REAL, Miguel. O romance português contemporâneo, 1950-2010. Lisboa: Editorial Caminho, 2012.

TENREIRO, Francisco José. Ilha de nome santo. Novo cancioneiro. Coimbra, 1942.

TORRES, Alexandre Pinheiro. O movimento neo-realista em Portugal na sua primeira fase. 2. ed. Lisboa: ICALP/Ministério da Educação, 1983.

TORRES, Alexandre Pinheiro. O neo-realismo literário português. Lisboa: Moraes Editores, 1977.

WILLIAMS, Raymond. Marxismo, estruturalismo e análise literária. In: Plural Revista do Programa de Pós-Graduação em Sociologia da USP, São Paulo, v. 21, n. 1, 2014. p. 195-216.

Recebido em 11/07/2016

Aceito em 9/09/2016 